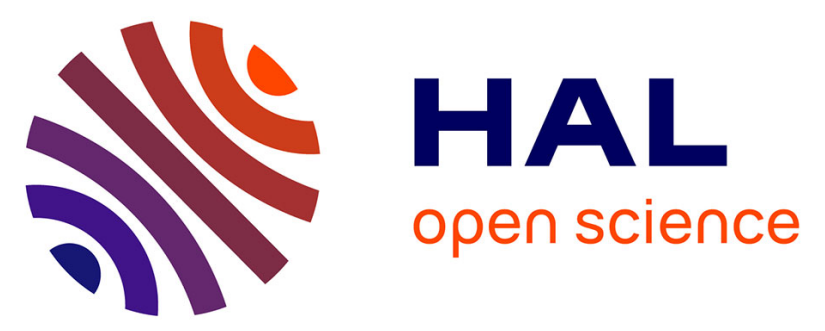

\title{
Prevalent material parameters governing spalling of a slag-impregnated refractory
}

\author{
Eric Blond, Nicolas Schmitt, Olivier Arnould, François Hild, Philippe \\ Blumenfeld, Jacques Poirier
}

\section{- To cite this version:}

Eric Blond, Nicolas Schmitt, Olivier Arnould, François Hild, Philippe Blumenfeld, et al.. Prevalent material parameters governing spalling of a slag-impregnated refractory. Key Engineering Materials, 2004, 264-268, pp.1751-1754. 10.4028/www.scientific.net/KEM.264-268.1751 • hal-00020484

\section{HAL Id: hal-00020484 \\ https://hal.science/hal-00020484}

Submitted on 22 Mar 2018

HAL is a multi-disciplinary open access archive for the deposit and dissemination of scientific research documents, whether they are published or not. The documents may come from teaching and research institutions in France or abroad, or from public or private research centers.
L'archive ouverte pluridisciplinaire HAL, est destinée au dépôt et à la diffusion de documents scientifiques de niveau recherche, publiés ou non, émanant des établissements d'enseignement et de recherche français ou étrangers, des laboratoires publics ou privés. 


\title{
Prevalent Material Parameters Governing Spalling of a Slag-Impregnated Refractory
}

\author{
E. Blond ${ }^{1}$, N. Schmitt ${ }^{1}$, O. Arnould ${ }^{1}$, F. Hild ${ }^{1}$, P. Blumenfeld ${ }^{2}$ and J. Poirier ${ }^{2-3}$ \\ ${ }^{1}$ LMT-Cachan (ENS de Cachan / CNRS-UMR 8535 / Université Paris 6) \\ 61 avenue du Président Wilson, F-94235 Cachan Cedex, France \\ ${ }^{2}$ CRDM / ARCELOR Grande Synthe, F-59381 Dunkerque Cedex, France \\ ${ }^{3} \mathrm{CRMHT}-\mathrm{CNRS}, 1 \mathrm{D}$ avenue de la Recherche Scientifique, F-45071 Orléans Cedex, France
}

Keywords: Refractory, Porous media, Cyclic thermal loading, Viscoplasticity

\begin{abstract}
In steel ladle linings, bauxite refractories in contact with iron and steel slag are subjected to complex loadings. To identify the causes of degradation in different reactor linings, a coupling diagram made up of three poles is established: namely, slag Impregnation (I), Thermomechanics (TM) and Phase transformations (P). The variation of the microstructure and the gradient of the chemical composition resulting from the (I-P) coupling are characterized by microprobe analyses; a natural impregnation tracer is identified. The (I-T) coupling is studied by modeling the refractory lining behavior subjected to a cyclic thermal loading within the framework of the mechanics of porous continua. Parameters governing the location and amplitude of the maximum pore pressure are obtained and their influences are studied. The analysis of the (TM) pole leads to the identification of a thermo-elasto-viscoplastic model for bauxite in various states of slag impregnation. Numerical simulations show that the stress state developed during the heating stages can induce spalling, probably generated by a localized over-pressure of slag.
\end{abstract}

\section{Introduction}

Refractories used in the steel industry to confine liquid metals have very variable life spans depending on the associated type and use, typically from half an hour for a casting submersible nozzle to several years for a blast furnace coating. These expendable products ensure staff safety and have an influence on the steel quality (i.e., bath temperature and pollution). Therefore, the control of the thermal, mechanical and physicochemical refractory behavior can be the source of significant improvements that can generate substantial financial savings.

Degradations of refractories result from strong interactions between mechanical, thermal and chemical phenomena, so that their analysis requires a horizontal transfer of knowledge. Here, the problem of coupling is dealt with from the mechanical point of view. Examination of the possible causes of damaged lining in several industrial reactors allows us to propose a coupling diagram (Fig. 1) with three poles: namely, Thermomechanics (TM), slag Impregnation (I) and Phase transformations (P). This approach is used to identify factors controlling spalling of bauxite-based working lining of steel ladles. The study of some couplings supposed to be dominant is privileged.

First, the analysis focuses on the (P/I) coupling. It helps us to characterize the different zones (e.g., impregnation, dissolution) for the refinement of the mechanical analysis. Second, the (TM/I) coupling is examined in the framework of the mechanics of porous media. The liquid slag pressure in the impregnated zone is evaluated during the manufacturing process. The last analysis deals with the (TM/P) coupling. A non-linear mechanical model is identified for non-impregnated and 
impregnated materials that accounts for a different behavior in tension and compression at high temperatures ranging from $1000^{\circ} \mathrm{C}$ to $1400^{\circ} \mathrm{C}$.

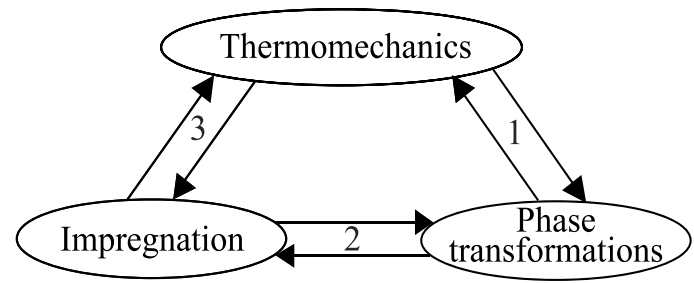

Figure 1: Coupling diagram

\section{Impregnation - Phase transformations}

Microstructure observations and chemical composition on a bauxite crucible impregnated in the laboratory and a sample taken from a steel ladle lining after its replacement have been performed by using a scanning electron microscope (SEM) and energy dispersive X-Ray spectroscopy (EDS). They help us to understand the interactions of type (1). Thermo-chemistry simulations with the software CEQCSI [1] on the crucible composition at different depth, coupled with permeability measurements, allow for the identification of four distinct zones of microstructure for a temperature of $1600^{\circ} \mathrm{C}$ : namely, a mushy/dissolved zone, an impregnated zone saturated with liquid, an unsaturated impregnated zone and an unimpregnated zone (Fig. 2a). The content variation of the liquid present in the solid skeleton of the brick at high temperature is also obtained. Moreover, it appears that phosphorus, present in the brick, can be used as a natural chemical impregnation tracer.

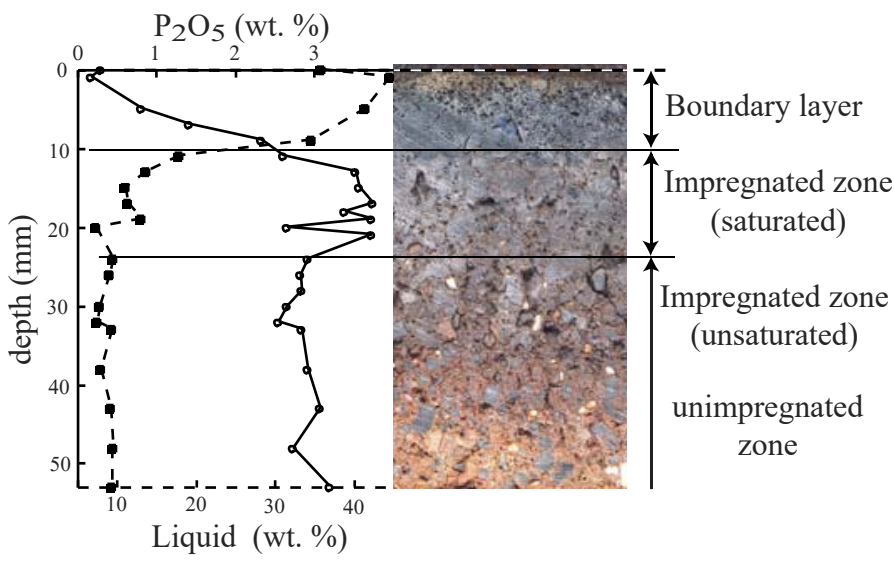

a) Synthesis of the study on the crucible test

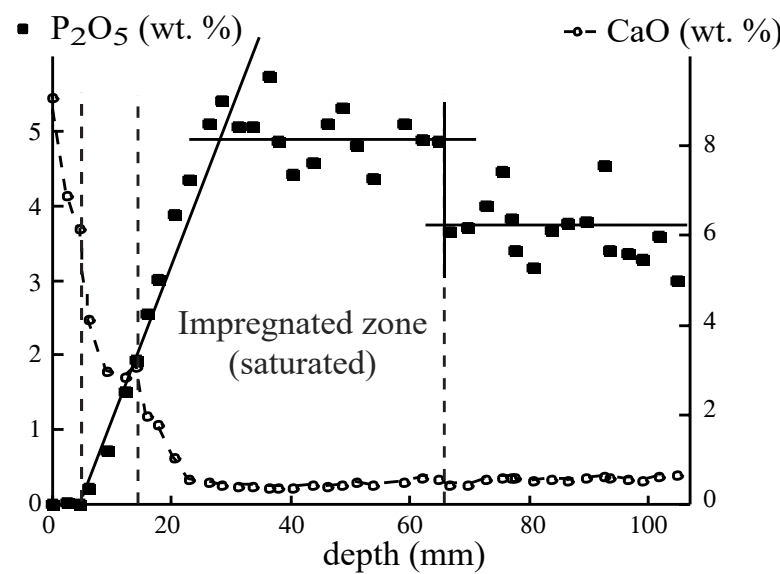

b) Synthesis of the post-mortem study

Figure 2: Principal results from the (I/P) couplings

This result is used to identify the liquid-impregnated zone of the brick taken from the steel ladle lining (Fig. 2b). Furthermore, it is observed that microcracks that seem to be at the origin of spalling are localized in this saturated impregnated zone. Finally, due to the high liquid content, the boundary layer appears to have no mechanical influence.

\section{Impregnation - Thermomechanics}

The steel-making process leads to a series of high and low temperature stages (i.e., full or empty vessels). An interstitial pressure of the liquid present in the refractory porosity appears and fluctuates with space and time, and induces stresses in the refractory brick. It is due to the relative 
bulk expansion variation $\delta_{\mathrm{v}}$ between the pore and the saturating liquid [3,4]. For the considered application, $\delta_{\mathrm{v}} \approx-10^{-5} \mathrm{~K}^{-1}$ is a reasonable estimate [3].

To evaluate the pressure field, the Impregnated zone is modeled as a porous medium: namely, the brick constitutes the skeleton, and the molten "slag" the saturating liquid phase. This is written within the framework of the mechanics of porous continua [2]. The calculation of the pressure leads one to solve both diffusion equations (i.e., heat transfer and liquid transport characterized by the thermal diffusivity $D_{T}$ and the hydraulic diffusivity $D_{H}$, respectively) and mechanical equations that are partially coupled [4]. For the sake of simplicity, the skeleton is assumed to be isotropic and thermoelastic with constant material coefficients. A reference pressure $P_{n d}$ is also defined by considering the case of a closed pore saturated by liquid. For the studied application, a good estimate is given by $P_{n d}=0.1 \theta_{\max }$ where $P_{n d}$ is expressed in MPa and $\theta_{\max }$ in ${ }^{\circ} \mathrm{C}$ [4].

The case of a one-dimensional half space submitted to a harmonic surface temperature is analyzed to characterize the effect of these prevalent parameters. It appears that heating is the critical stage. Analytical expressions are established for the maximum dimensionless pressure $P_{\max } / P_{n d}$ and the location $x_{c r}$ of the latter characterized by a dimensionless critical abscissa $X_{c r}$ [4]. These expressions only depend on the diffusivity ratio and the real location is mainly dependent on the inverse of the square root frequency of thermal loading. These results are summarized in Fig. 4.

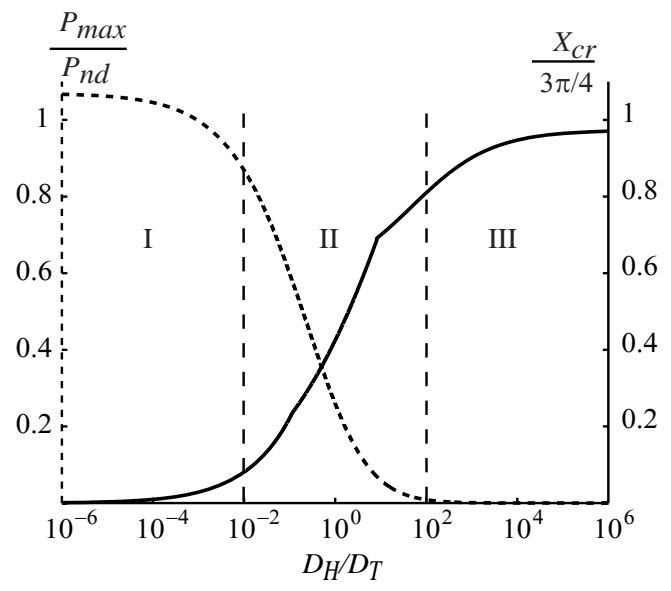

a) Maximum dimensionless pressure and dimensionless location

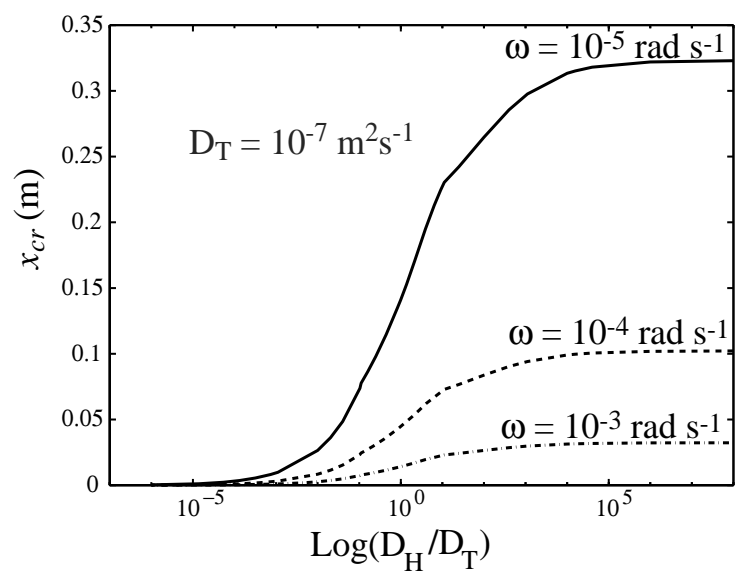

b) Influence of the thermal loading frequency on the real location of the maximum pressure

Figure 4: Saturated porous half-space submitted to a harmonic thermal loading: summary of the results

Depending on the diffusivity ratio, three zones can be observed on the curve drawn in Fig. 4a. In the first one (I), a high pressure appears close to the hot face, which must yield thin spalls. In the second one (II), a larger critical abscissa with a lower pressure is likely to initiate larger spalls; it depends on the material strength. In the last one (III), the pressure is too low to create spalls. As shown in Fig. 4b, the real spall thickness also depends on the frequency of the thermal loading.

\section{Thermomechanical behavior of bauxite under different slag impregnation states}

To analyze the non-linear behavior, compression and three-point bend tests have been carried out at high temperatures (ranging from $1000^{\circ} \mathrm{C}$ to $1400^{\circ} \mathrm{C}$ ) under various slag impregnation states. It is noted that bauxite experiences a non-linear thermomechanical behavior, which is different in tension and compression. An adapted thermoelastic-viscoplastic model is written by considering a single-phase medium [3] and the constitutive equations are identified from test data (Figs. 5). This 
model, which is implemented in the finite element code ABAQUS, allows us to carry out simulations on an axisymmetric structure representative of a steel ladle. The results obtained show very low stress levels and no plastic strain localization inside the lining as observed for the pressure. Furthermore, the frequency of the cyclic thermal loading seems to have little influence on the results. It is reasonable to conclude that the non-linear mechanical behavior of bauxite considered as a single-phase medium cannot justify alone the observed degradations.

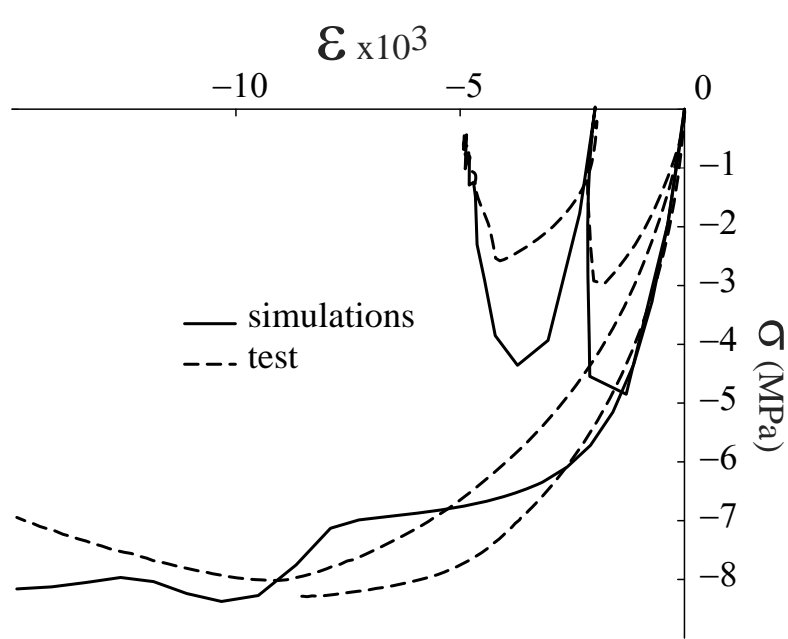

a) Compression tests

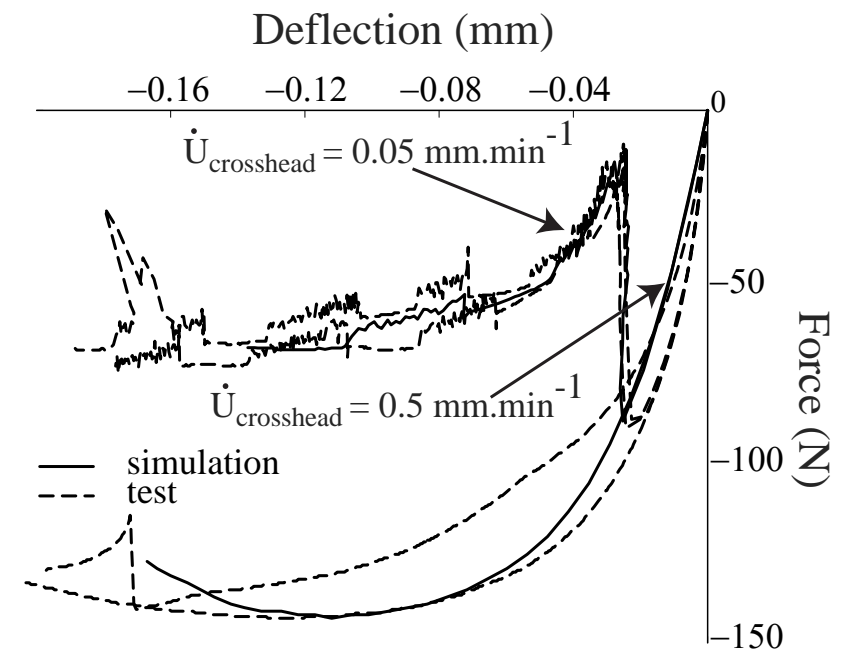

b) Three-point bend test

Figure 5: Experimental results and identification for the impregnated refractory at $1250^{\circ} \mathrm{C}$

\section{Conclusion}

In this work, a coupling diagram is proposed to study the degradations of refractories in contact with molten slag. By using this framework, the impregnation spalling of the bauxite working lining of steel ladles has been investigated. This coupling diagram gives a global view that permits us to study the major interactions between slag Impregnation, Thermomechanics and Phase transformations.

First, it appears that, for the in-service temperature range, a liquid phase penetrates into the porosity of the brick and saturates a zone of several centimeters. This liquid phase has not the chemical composition of slag. It varies with the depth so that it is in equilibrium with the bauxite skeleton. Second, the presence of fluid, coupled with the cyclic thermal loading, generates a fluctuation of the interstitial pressure. The study of that phenomenon allows us to estimate the maximum pressure in use, and its location. Third, a modeling of the thermomechanical behavior of bauxite at high temperature enables us to carry out numerical simulations to evaluate stress and strain fields in the lining. A local over-pressure, coupled with the low biaxial compressive stress field must be at the origin of the impregnation-spalling observed in steel ladles. To confirm this hypothesis, further investigations coupling both approaches will be undertaken in the future.

\section{References}

[1] J. Lehmann, M. Boher, H. Soulard and C. Gatellier, Metal/Refractory Interactions: A Thermodynamic Approach, Proc. Unitecr'01, pp. 23-36, 2001.

[2] O. Coussy, Mechanics of Porous Continua, John Wiley \& sons, 1995.

[3] E. Blond, Dégradation thermomécanique des réfractaires au contact de laitiers sidérurgiques, Ph. D. Thesis, in French, LMT-Cachan, ENS de Cachan, France, 2003

[4] E. Blond, N. Schmitt and F. Hild, Response of Saturated Porous Media to Cyclic Loadings, Int. J. Analyt. Num. Meth. Geomech., 27 (11), pp. 883-904, 2003. 